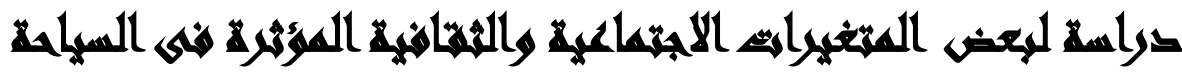

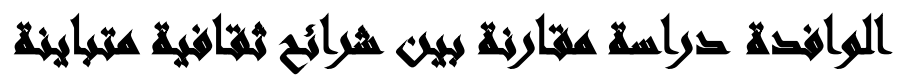

[ฯ]

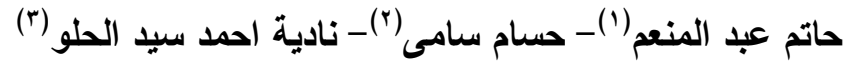

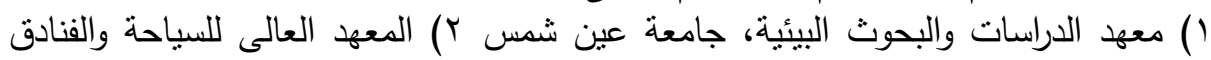
r) وزارة السياحة

\section{المستخلس}

تعد مصر من الدول السياحية التى يعتمد فيها على النشاط السياحى كأحد الحلول لزيادة النقاة

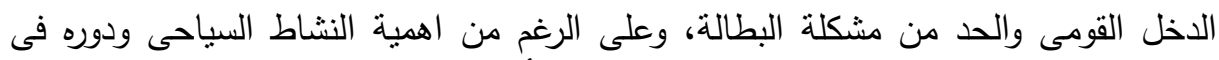

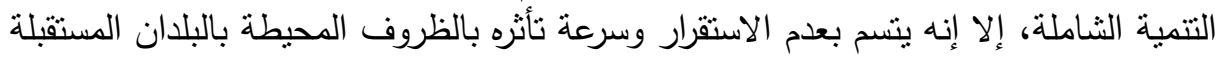

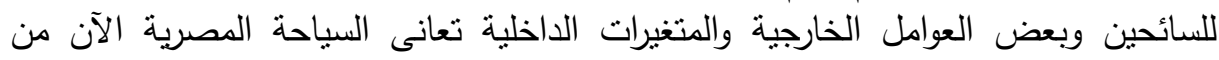

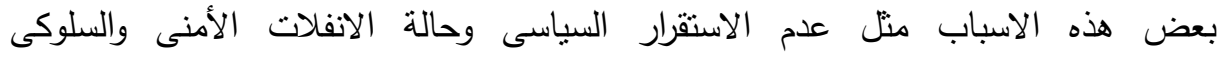

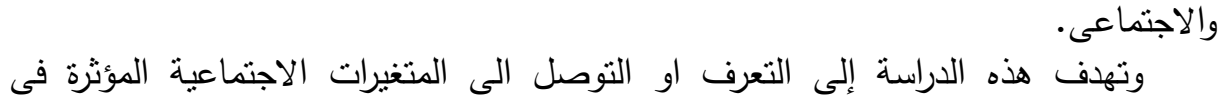

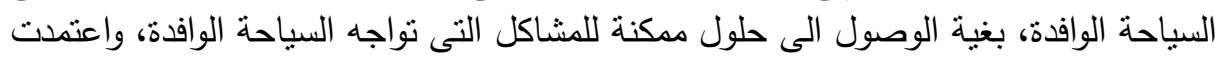

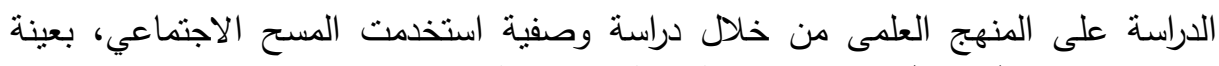

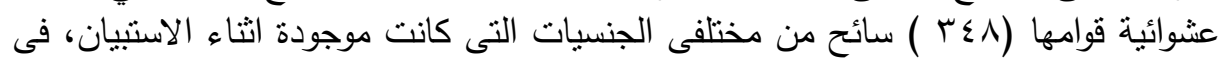

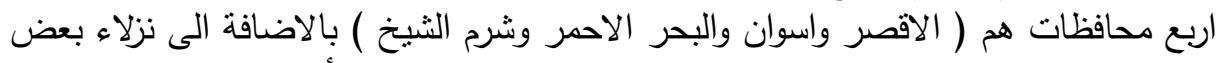

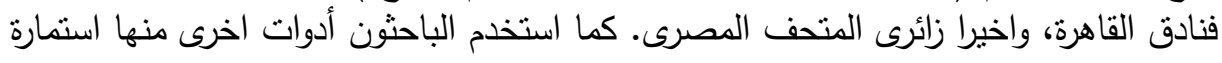

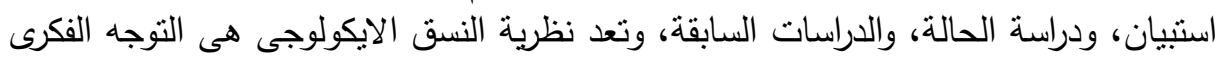

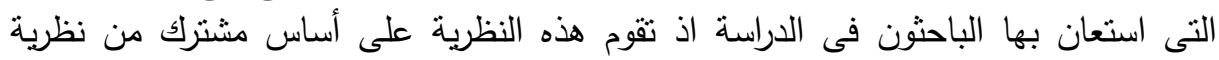

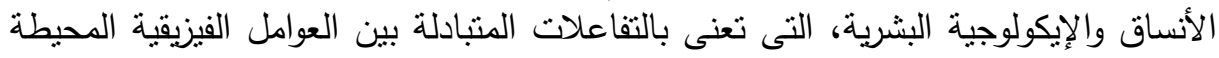
والكائنات الحية.

وتوصلت الدراسة إلى عدد من النتائج الهامة منها:

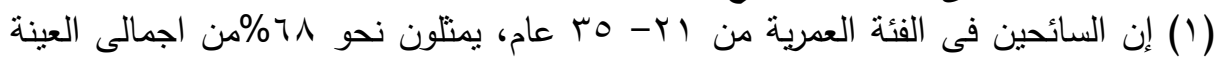

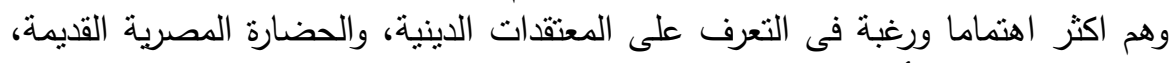

والسياحة الثقافية والأثرية، السياحة الدئية النئية.

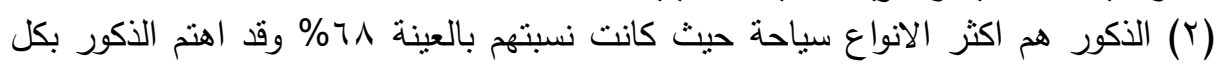

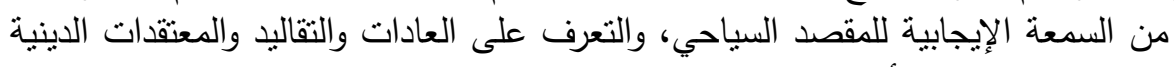
للسكان المحليين، والأنشطة الترفيهية.

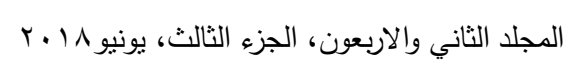




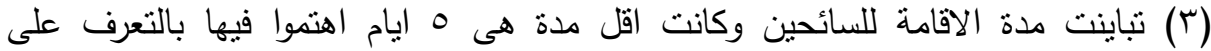
العادات والثقاليد والمعتقدات الدينية للسكان المحليين، والأنشطة الترفيهية والحياة الليلية،

• التعامل مع المشكلات الاجتماعية باعتدال لا بالتهويل او التهوين للحفاظ على سمعة

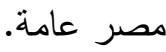

النهوض بمصر سياحيا من خلال تتمية الوعى السياحى لدى جميع الفئات بأهمية السياحة

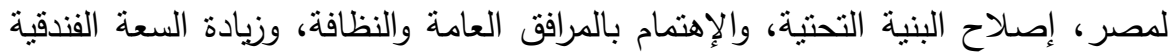
وفق الإحتناجات والأثار البيئية.

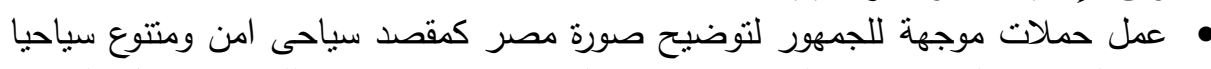

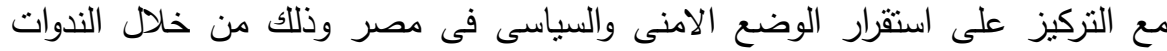

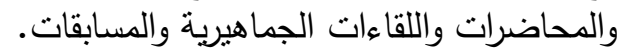

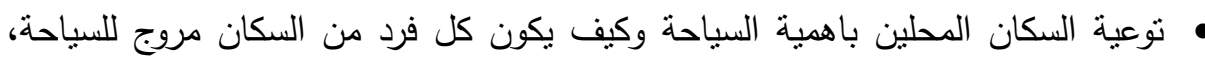

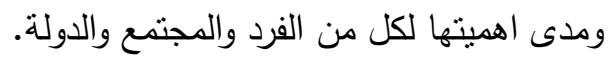
• قيام المؤسسات الثقافية الحكومية بإنشاء آليات للتواصل عبرلة شبكات التواصل الاجتماعى.

\section{المهanat}

لقد أصبحت السياحة ظاهرة اجتماعية وثقافية كبرى يشارك فيها السائحين والمجتمعات

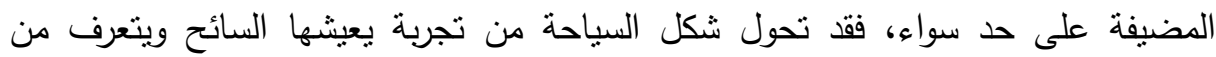
خلالها على شعبها وثقافته إلى أداة لتحقيق السلام، بالإضافة إلى حركة النقل التى أصبحت

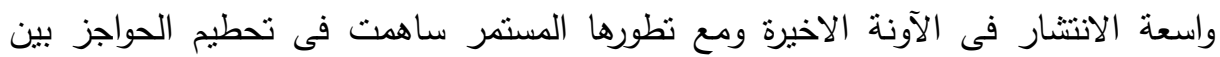

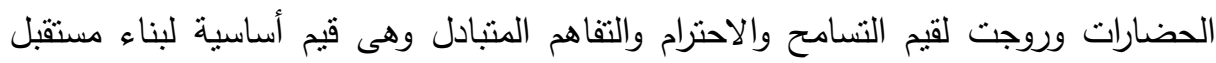

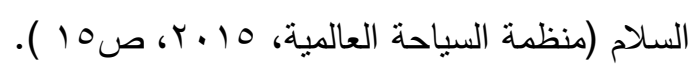

ورغم الأهية الكبيرة والفوائد العديدة للنشاط السياحى ودوره في التتمية الثاملة، إلا إنه

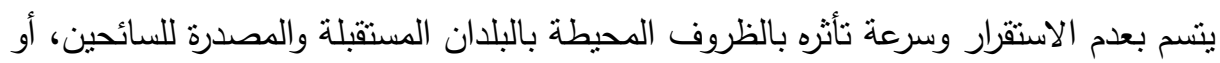

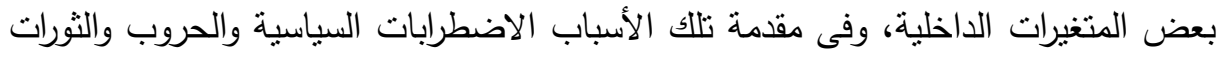
والكوارث الطبيعية والتقلبات المناخية وظهور بعض التيارات غير المرحبة السياحة متلما تعانى 
السياحة المصرية الآن من بعض هذه الاسباب مثل عدم الاستقرار السياسى وحالة الانفلات

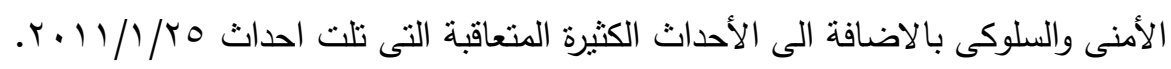

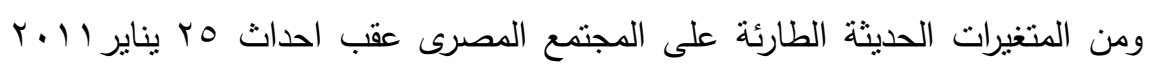
ظهور بعض التيارات التى حاولت وضع إطار قيمى وأخلاقى جديد لتتكيل صورة النشاط

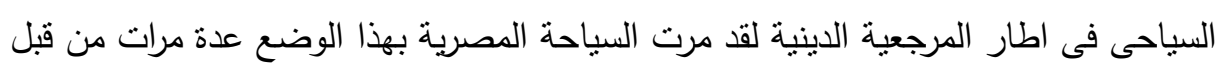

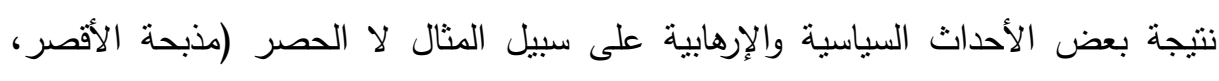

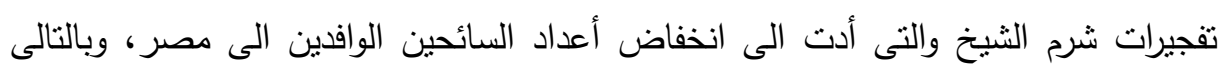

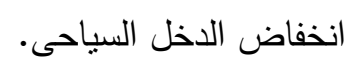

\section{مش2/}

هناك بعض المتغيرات التى طرات على المجتمع المصرى مثل ( تراجع القيم الاصيلة والاخلاق، عدم الالتزام بآداب الحوار، العنف، وعدم احترام القانون بل والتجرؤ عليه)

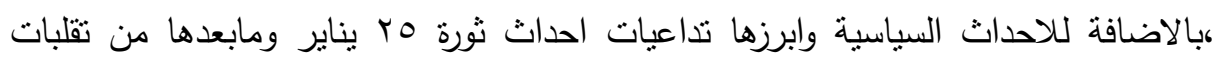

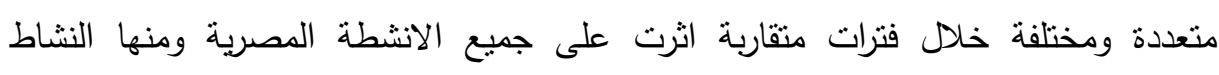

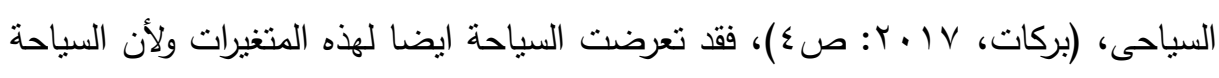

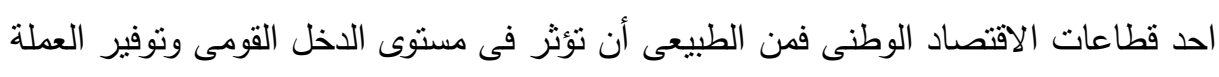

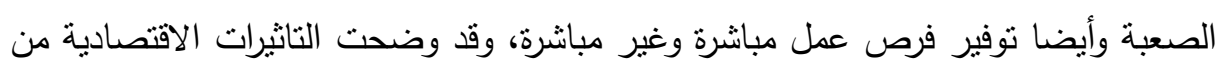

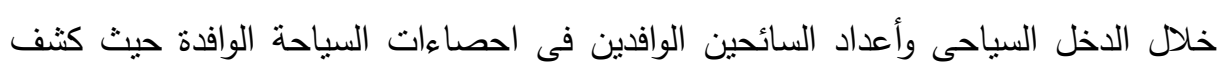

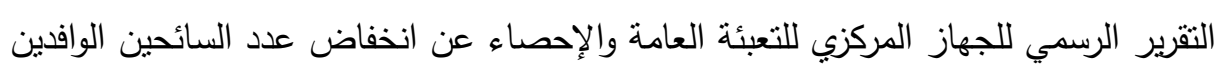

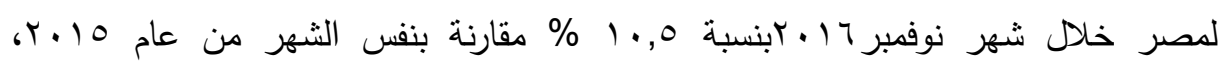

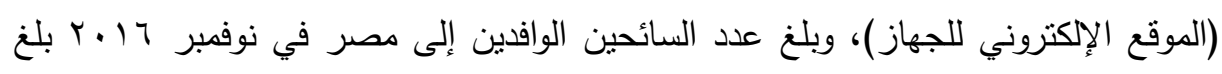

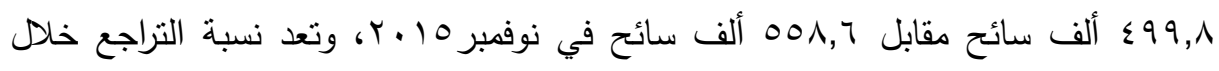

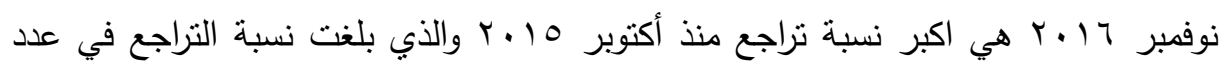

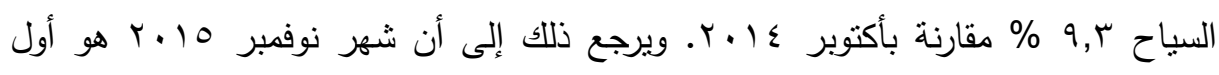
الثهور التي تأثرت فيها السياحة في مصر بحادث سقوط طائرة الركاب الروسية في سيناء

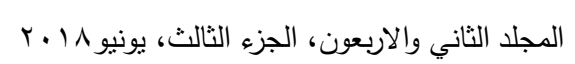


فور أقلاعها بدقائق من مطار شرم الثيخ وأسفرت عن مصرع گ گr شخصًا وذللك في الحادي والثلاثثن من أكتوبر 10 ـr، واخذت عدة دول قرارات بعد الحادث بحظر الرحلات إلى شرم

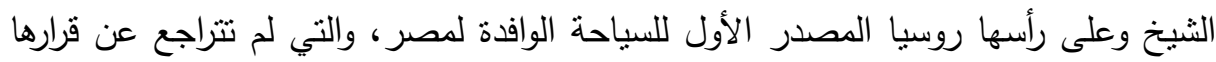

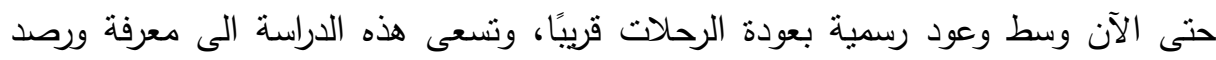

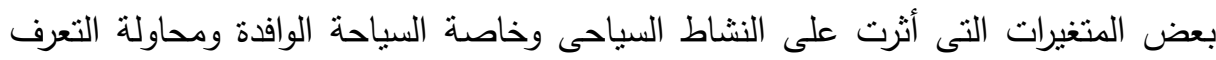
على الأسباب التى ادت لذلك والوصول الى بعض التصورات المحتملة من السائحين والثرائح الاجتماعية والسياحية والدينية المختلفة لحلها ومدى تأثثر هذه المتغيرات على السياحة وكيفية استعادة هذا النشاط لقوته، خاصة وأن هناك متغير سلبى واضح وملموس وهو تفشى ظاهرة الإنحدار الأخلاقى والقيمى الذى أصاب البعض وظهر على السطح بصورة لافتة فى أثنياء

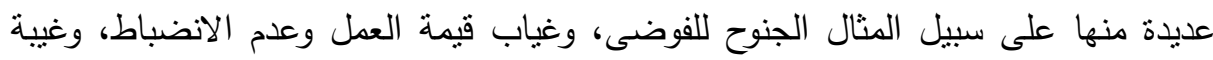

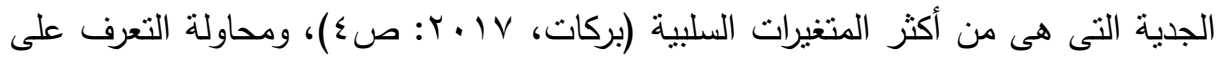

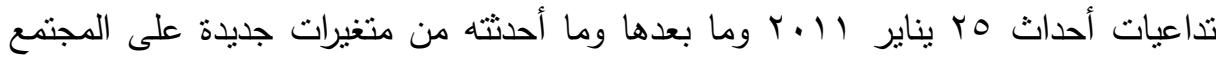
المصرى داخليا وخارجيا وهل هنالك أسباب أخرى تؤثر على مصر أم هـى المتغيرات الجديدة

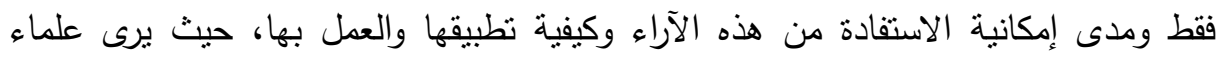

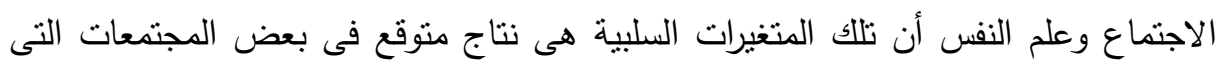
تتعرض لأحداث جسام ووقائع مصيرية وتحولات كبيرة فى ظل ما يجرى منها من مواجهات

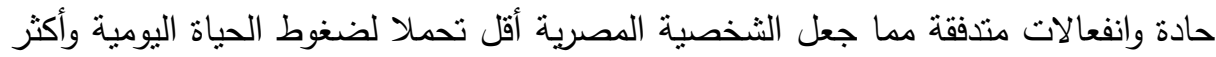
ميلا للانفعالات الحادة وأكثر استعداد للاندفاع نحو الفوضى والعنف اللفظى والجسدى ( حفنى

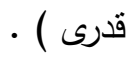
من خلال ما سبق يتضح ان مشكلة البحث الحالى ترتكز حول السؤال الرئيسى الآتى:

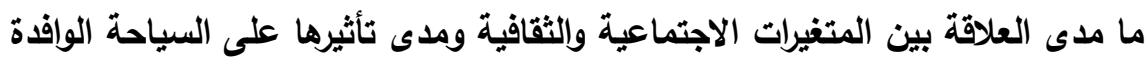

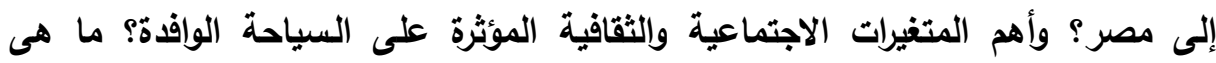

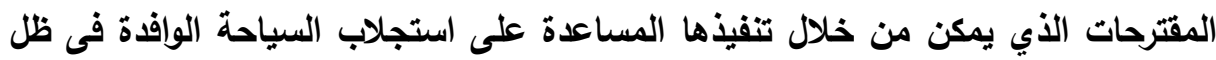

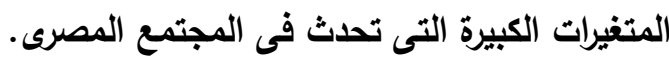




\section{تساؤلايت التراسة}

تقوم الدراسة على عدد من التساؤلات هى:

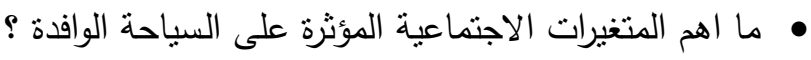

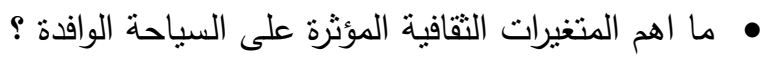

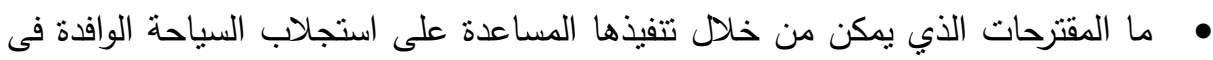

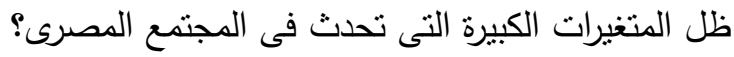

\section{أهمية الصوراسما}

الأهمية النظرية: تعد الدراسة هامة من عدة جوانب فهى دراسة جديدة تتناول موضوعاً معاصراً وحديثاً وهو تأثير المتغيرات الاجتماعية على السياحة الوافدة حيث أن هذه هنه الدراسة تربط بين المجتمع ومتغيراته التى تشمل العادات والتقاليد بالإضافة إلى الأمن والسياسة وتاثيرهما على السياحة حيث أنه لا توجد سياحة بدون استقرار سياسى وأمنى لأن السياحة

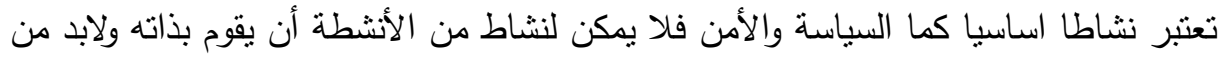
الدمج او التكامل والتتسيق وخاصة أن مثل هذه الدراسة فى مرحلة غير مستقرة سياسياً وأمنياً

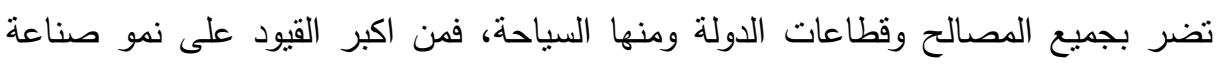
السياحة عدم الاحساس بالأمن والذى يعتبر اكبر الحواجز امام المستثمر وكذا الاستقرار

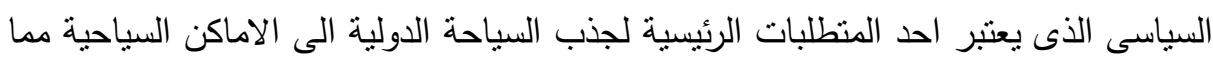

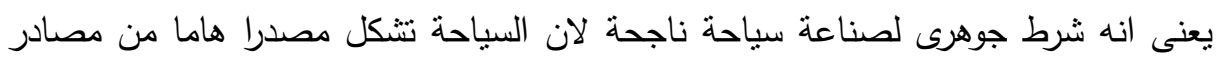

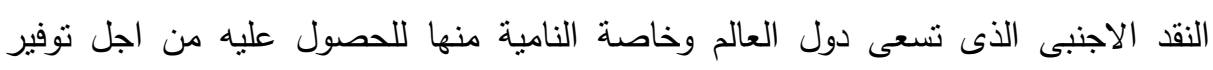
حاجاتها من مستلزمات التتمية من القطاعات الاقتصادية الاخرى. الأهمية التطبيقية: ويستمد هذا البحث أهميته من عدة محاور: • اهية النظرة الثاملة للعوامل الاجتماعية والثقافية للنشاط السياحى.

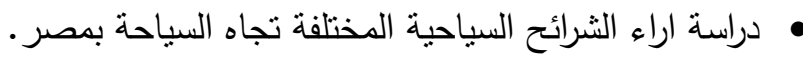
• دراسة اراء الخبراء حول معوقات السياحة وطريقة حلها. 
الأهمية الاجتماعية للسياحة: نرى الدراسة الحالية أن لكى يتم تطوير السياحة يجب تتمية بعض الكفاءات العمالية فى مجال القطاع السياحى وزيادة فرص وإمكانية التوظيف فيها ولتحقيق ذلك يجب نطور برامج التعليم لتكون أكثر ملاعمة لسد احتباجات السوق السياحى، تتجيع المشروعات الصغيرة وصغار المستثرين لتحقيق مواصفات جودة خدمية سياحية عالية تجذب السائح إليها، تتمية المدخرات والاستثمار القومى فى السياحة للارتقاء بمستوى السياحة

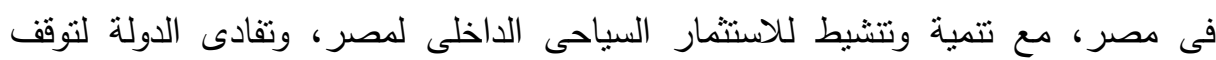

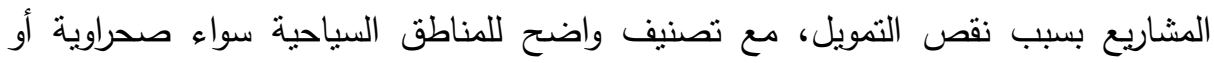

\section{أهصا اهن التصولمد}

$$
\text { ويهذف البحث الى التعرف على: }
$$

• • أهم العوامل الاجتماعية والتقافية المؤثرة فى السياحه الوافدة.

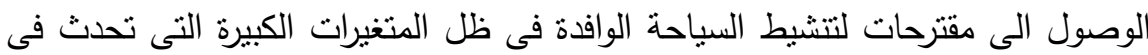

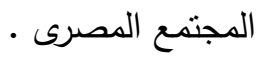

2

\section{هذاهيهر القراسهة}

ا ـ مفهوم السياحة لغوياً: ذكر في معجم مقاييس اللغة " بأن السين والياء والحاء أصل صحيح، وقياسه قياس ماقبله،وهو (سيح) فانهما يدلان على استمرار الثيء وذهابه" يقال : ( ساح في الأرض يسيح سياحة وسيوحا وسيحانا، أي ذهب لقضاء حاجة معينة ولأسباب وأهذاف عديدة ضمن سيكولوجية وفسيولوجية الانسان اللنان تحركانه نحو هدف

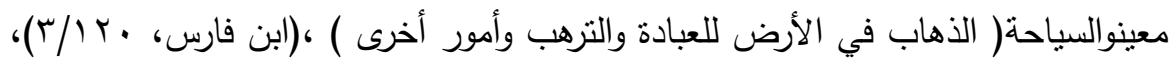

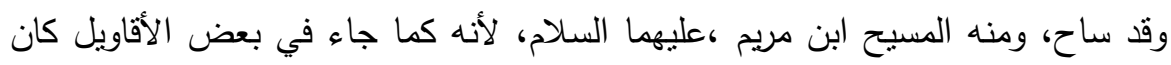
يذهب في الأرض كلما أدركه الليل صف قدميه وصلى حتى الصباح، فاذا كان كذللك فهو 
مفعول بمعنى فاعل، " وأما عيسى فقيل سمي بذلك لأنه كان يمسح الأرض بسياحته" (ابن

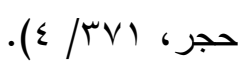

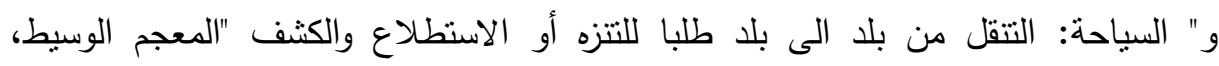
(Y/乏TV)

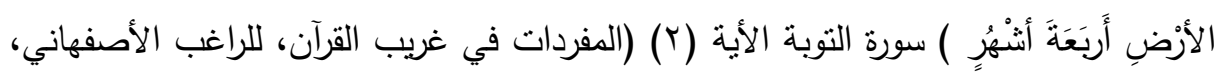
ص قيل في معجم مقاييس اللغة:" وما يدل على صحة هذا القياس هو قولهم : ساح الظل اذا فاء"(ץ) أي رجع من المشرق الى المغرب (ابن فارس، مرجع سبق ذكره ) .

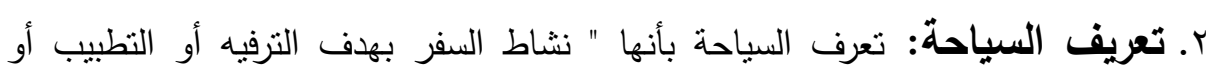

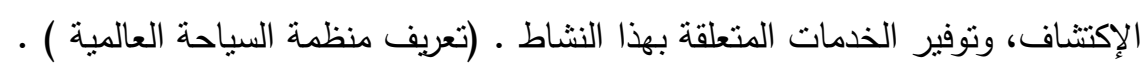

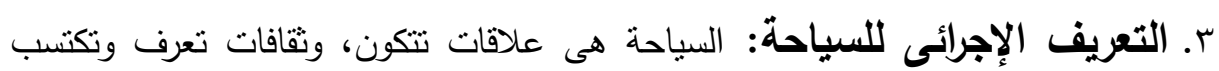
والغرض منها هو الاستمتاع والمغامرة والتعرف على كل ما هو جديد واكتشاف كل ما هو

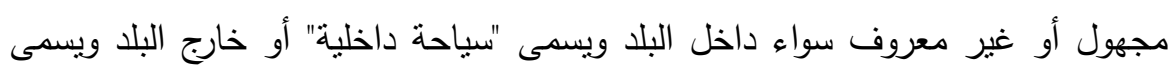

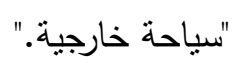

ع. تعريف السياحة الوافدة: هى السياحة التى يقوم بها القادمون او الوافدون من غير

$$
\text { سكان الدولة (تعريف منظمة السياحة العالمية) . }
$$

\section{هـ المفهوم الاجرائى للسياحة الوافدة هو:}

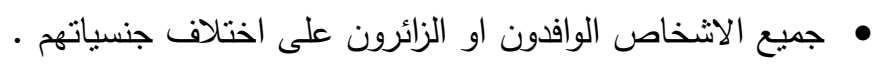

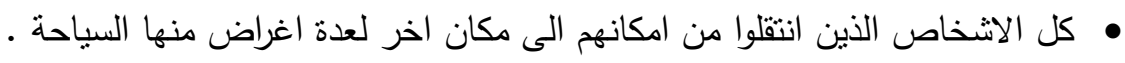

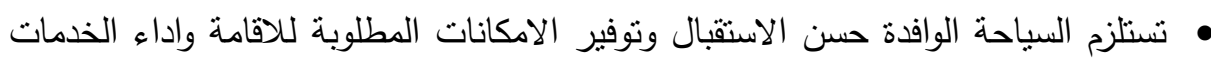

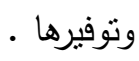

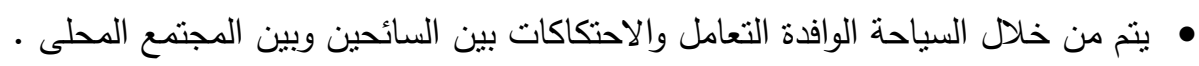

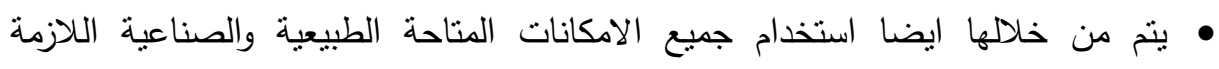


I. تعريف السائح: " السائح هو ذلك الثخص الذي يقوم بالانتقال لغرض السياحة لمسافة ثمانين كبلومترا على الأقل من منزله ". ( تعريف منظمة السياحة العالمبة) . V. المتغيرات الاجتماعية وإلثقافية: المتغيرات لاتبق على وتيرة واحدة وتتثمل مستويات رقمية مثل ( السن - والدخل - الجنس - التعليم - المهنة ) ومستويات مكانية اوسكنية منل (الحضروالريف) ومسنويات وظيفية منل ( ادارية - كتابية - فنية ) ومتغيرات جنسية مثل (المصرية، السعودية ) بوابة المجتمع، موقع المعرفة، • ( • ص ص • (Y). ^. مفهوم العوامل الإجتماعية والثقافية اجرائيا: يقصد بالعوامل الإجتماعية والثقافية هى كل مايتصل بالفرد ويؤثر فى سلوكه وعلى مسنوى أدائه وكذلك التفاعل بينه وبين

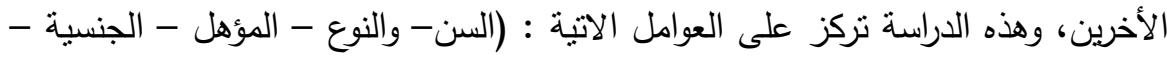
الغرض من الزيارة - مصادر المعلومات- الديانة - عدد مرات الزيارة الدخل - الوظيفة ).

\section{الصراسايت المايرية}

تتاولت الدراسات السابقة التى رجعت اليها الباحثة العديد من المتغيرات سواء البيئية او الحرفية او الثقافية اوالتوزيع السكاني او الاقتصادية المؤثرة فى البيئة السياحية المسقبلة للسائحين وتناولت الدراسات السابقة" :دور السياحة فى إعادة نوزيع الخريطة السكانية لدصر" (بسرى،

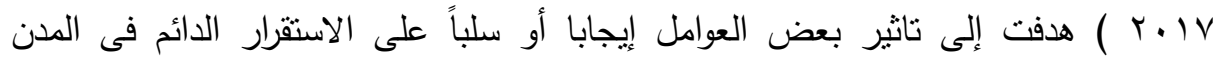
الساحلية، ودراسة تفعيل دور السياحة في التنمية الريفية "مع دراسة حالة في المنطقة الساحلية

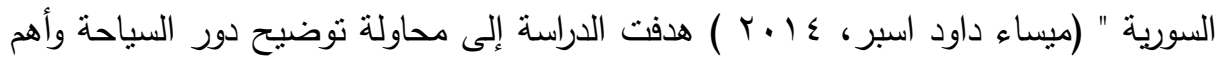

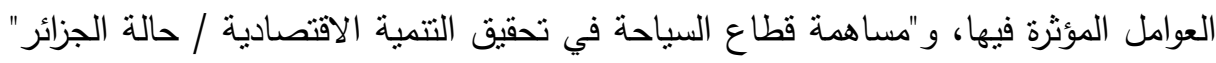

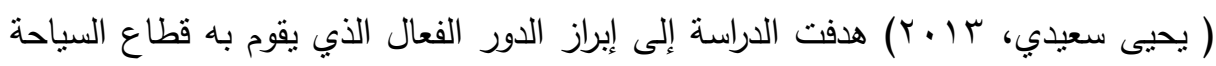

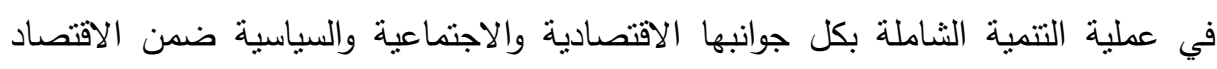
العالمي وتسليط الضوء على واقع مساهمة القطاع السياحي في عملية التتمية الاقتصادية الجزائرية، "تنمية السياحة البيئية دراسة تطبيقية على منطقة الوادى الجديد" (راناعلى عبد

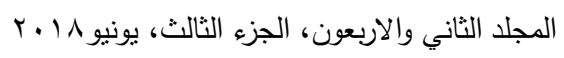




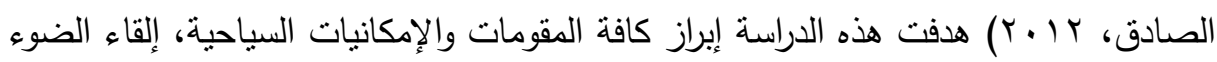
على أهمية التوازن بين البيئة والتتمية السياحية وصولا إلى أهمية تنمية السياحة البيئية

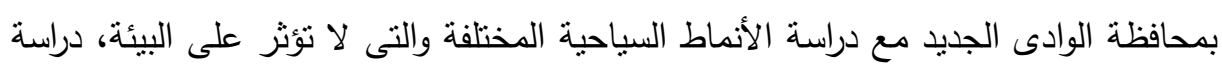

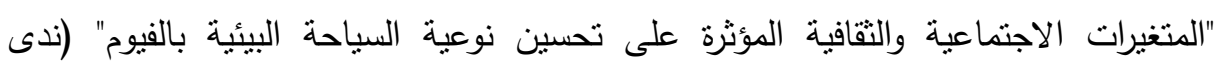

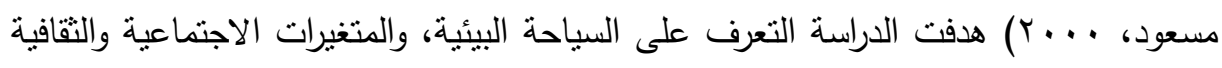
التى تعوق عملية تحسين السياحة البيئية بالفيوم كعنصر جذب سياحي، ودراسة الوضع الراهن

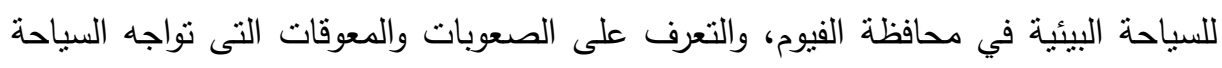

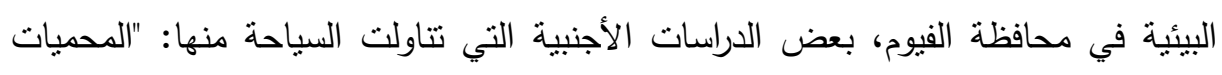

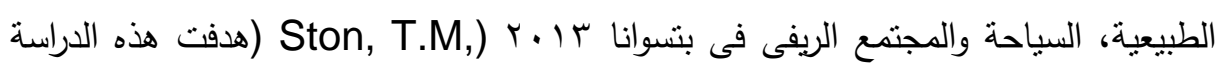

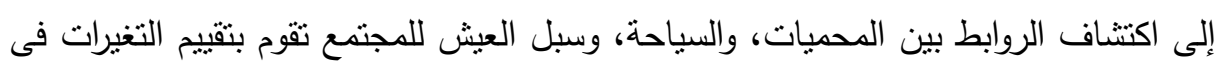

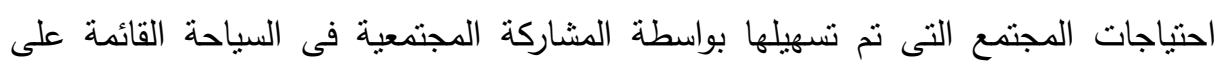

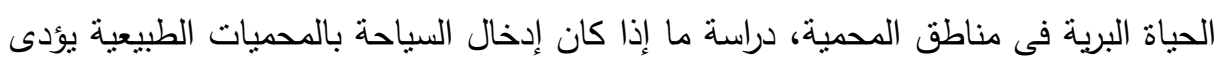

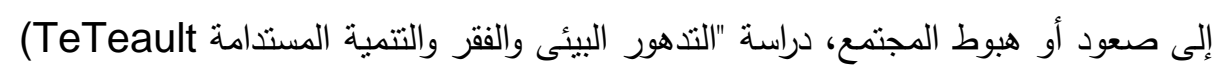

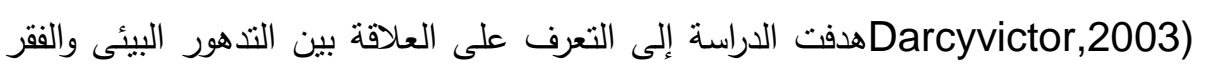

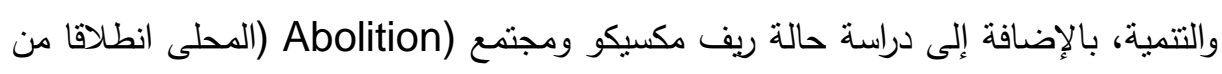

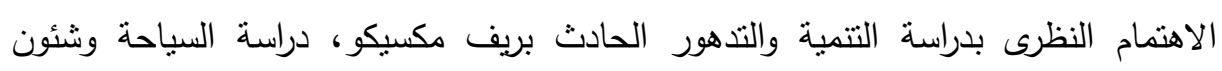

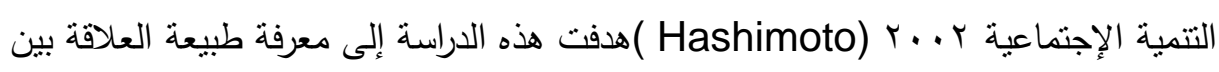

$$
\text { التتمية السياحية والتغير الإجنماعى.) }
$$

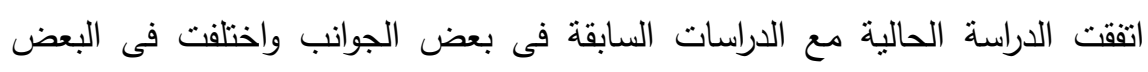

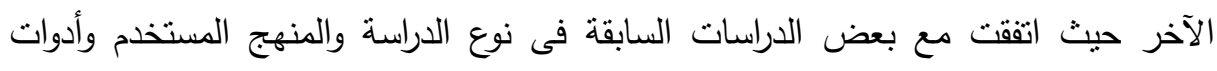

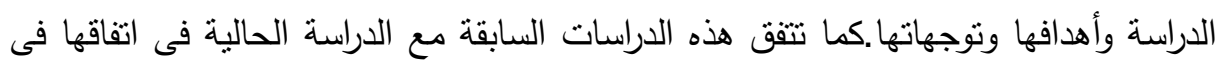

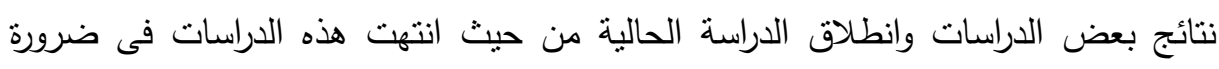
التعرف على بعض العوامل الاجتماعية المختلفة. 


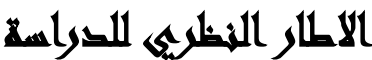

تمثل المنطلق النظري لهذه الدراسة في عدد من النظريات منها: نظرية النسق الايكولوجى: نساعد نظرية النسق الإيكولوجى على تتمية منظور جديد يوصف بأنه تطورى تكيفى يعتمد على التفاعلات المتبادلة والمستمرة بين كل عناصر البيئة، فإذا كانت البيئة تؤثر فى البشر ، فإن البشر أيضا يؤثرون في البيئة سواء بمفهومها الفيزيقى أو لئه

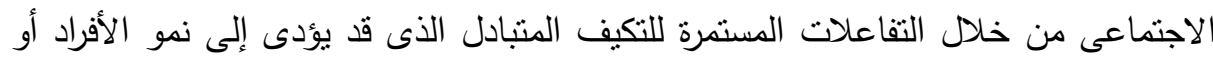

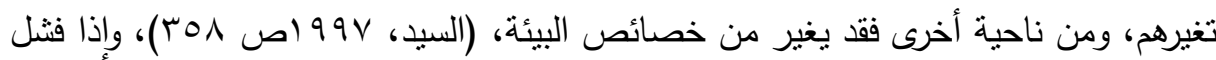
هذا التكيف المنبادل حدثت مشكلات للطرفين، ومن هنا تهنم النظرية الإيكولوجية بكل من العوامل الداخلية والخارجية المؤثرة فى النسق الإيكولوجى والمواطنون لهذا النموذج ليسوا أفراداً

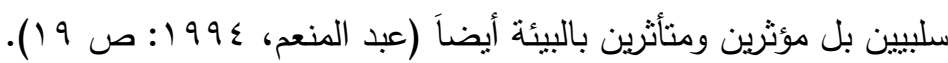

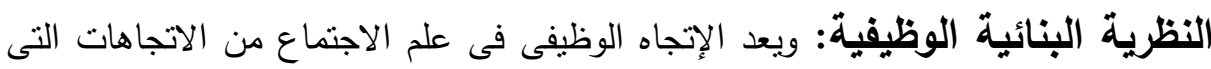
تعنبر نتيجة لترشيد إنتاج المعرفة المتعلقة بالمجتمع وبمجرد اكتماله فإنه يتولى ترشيد حركة الإه

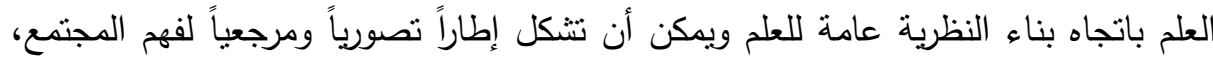
بحيث يصبح تبنى هذا الاتجاه فى عملية البحث الاجتماعى، وكذلك فى سعينا لفهم الدجمع وتفسير تفاعلاته الآلية لتحقيق التراكم المنظم للوصول إلى نظرية عامة وهو ما يهدف إليه الباحثون فى علم الاجتماع (ليلة،

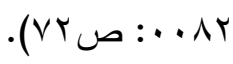

نظرية الدور: أى تغيير فى البناء الاجتماعى يؤدى بدوره إلى تغيير القيم الاجنماعية

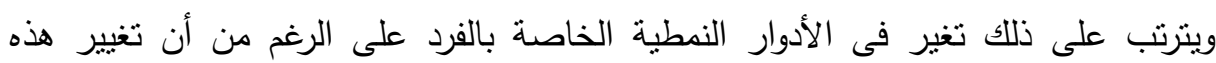

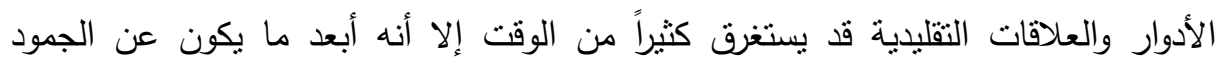

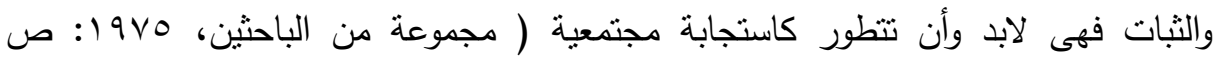


نظرية التحدي التحديث يؤكدون ضرورة تبنى النموذج الرأسمالى الغنى حتى تصل

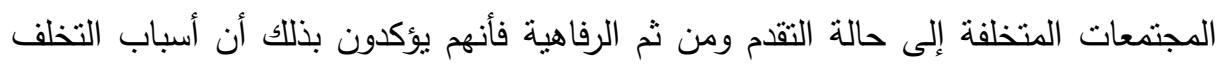

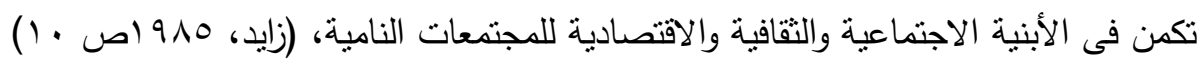

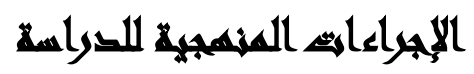

نوع الدراسة والمنهج والأدوات المستخدمة: تتنمي هذه الدراسة إلى الدراسات الوصفية لكونها من انسب أنواع الدراسات ملائمة لطبيعة موضوع الدراسة، وقد استخدم الباحثون المنهج

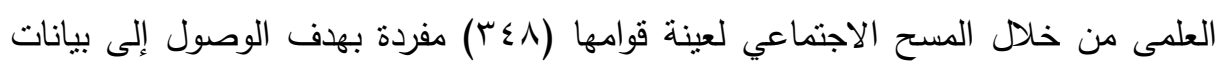

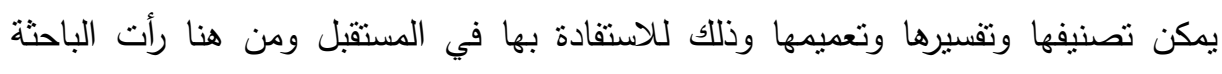

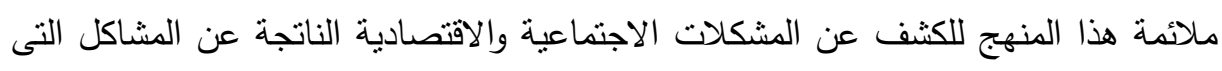
تواجه السياحة . ملهده

الأدوات التي استخدمها الباحثون هي: استمارة سنبيان مكونة v محاورتحتوى على بـ سؤال للكثف عن العوامل الاجتماعية والثقافية، والخدمية والتكنولوجية التى تواجه السائحين،

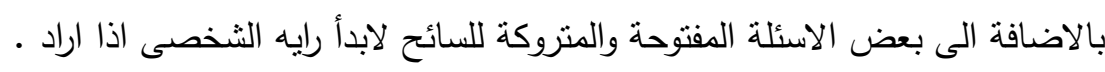
معامل الصدق والثبات: قام الباحثون بعرض صحيفة الاستبيان على "مجموعة من أساتذة

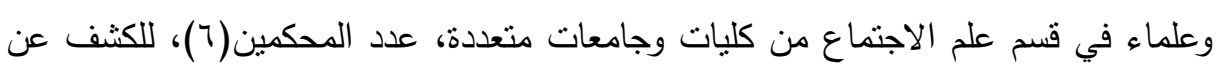
مدى استيفائها للهدف الذي وضعت من أجله، وتم تقنين الأسئلة وتعديل الاستمارة بناء على الألى

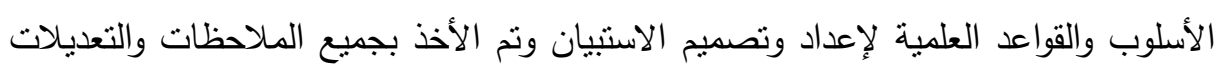

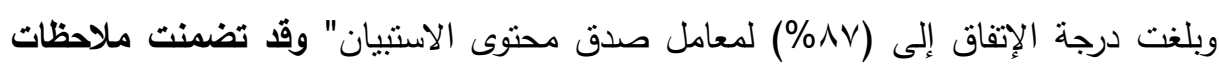
لجنة المحكمين عدة نقاط أهمها:

• إعادة صياغة بعض العبارات مثل حذف السياحة الروحية واستبدالها بالسياحة الدينية.

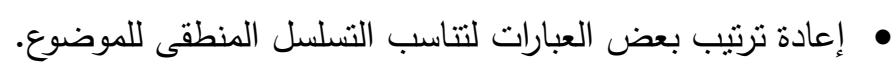


• وكذلك اختبار الثبات باستخدام معادلة "هولستاى" لقياس معامل الثبات، وفقد بلغ معامل

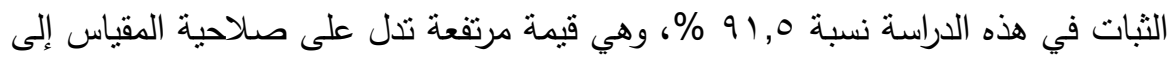
حد كبير.

شروط اختيار عينة البحث: تم البحث على عينة مكونة من ^§؟ من السائحين مجتمع الدراسة والتى تم توزيعها في بعض الفنادق الثنابتة بمحافظة القاهرة ومدينتى شرم الثشخ والغردقة، وبالفنادق العائمة بكل من محافظتى الاقصر واسوان واخيرا بالمتحف المصرى،

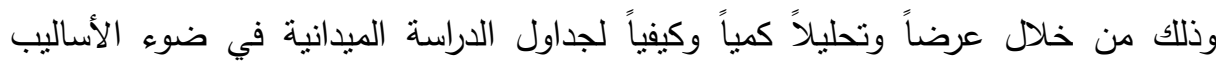
الإحصائية المستخدمة في استمارة الاستبيان، وتفسير نتائج الجداول والنتائج المتعلقة بالدراسة الميدانية بهدف التعرف على مدى تاثثر العوامل الاجتماعية والفيزيقية ومتوسط الاقامة والغرض من الزيارة وتكرارها على الاسباب الرئيسة والمؤثرة فى اقبال او انحسار السياحة الوافدة الى مصر للتعرف عن قرب ما يعزز الميزة التتافسية التى تتمتع بها مصر بين المقاصد السياحية الاخرى، لان اساس النشاط السياحى هو مجموعة المقومات الطبيعية

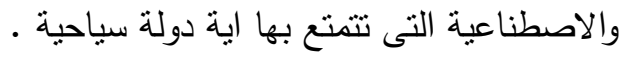
وقد اتصفت عينة الدراسة من المبحوثين باختلاف كل من ( السن، النوع، الجنسية، الديانة، دهاهية مستوى التعليم، مدة الاقامة، سبب الزيارة، عدد مرات الزيارة، الدخل، الوظيفة ) .

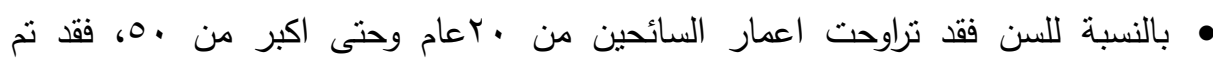
الحرص ان يشمل الاستقصاء سن الثباب والنضج وحتى الثيخوخة . • وايضا النوع فقد شمل الذكور والاناث ولم تكتف الباحثة بنوع واحد فقط من السائحين

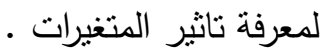
• ومن خلال الاستقصاء اتضح ان الجنسيات التى كانت متاحة حوالى ؟ ؟ جنسية مابين جنسيات عربية واجنبية وافريقية واسيوية، بالاضافة الى عدد من السائحين لم يدونوا

$$
\text { جنسياتهم جنائ }
$$

• وبالنسبة لعنصر الديانة فكانت مابين الاسلامية والمسيحية والهندية والبوذية وقد فضل

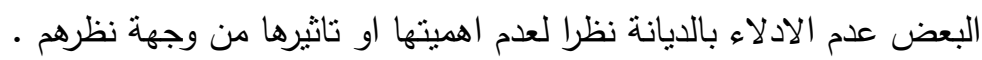

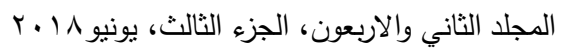


• اما مستوى التعليم فكان مابين الدراسات العليا والجامعى والمتوسط، ومن لم يحصل على شهادة.

وبالنسبة لمدة الاقامة فقد تزاوحت المدة الزمنية من يوم الى 10 يوما ـ

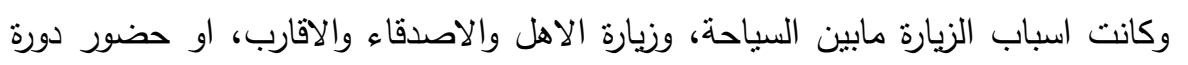

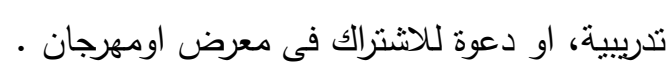

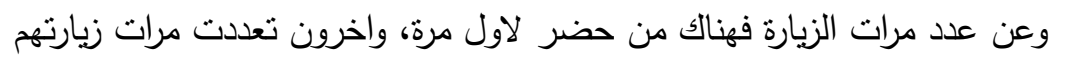

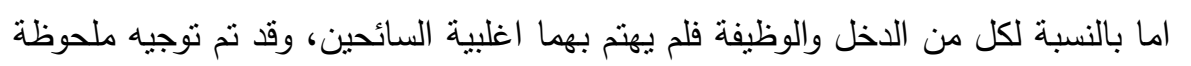
من السائحين اثثاء الاستقصاء بان كل من ( الديانة والدخل والوظيفة ) لا تهم احد .

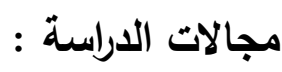
أ- المجال البشري: عينة عشوائية من السائحين الوافدين من جنسيات مختلفة . ب-المجال الجغرافي: اجريت هذه الدراسة فى مصر فى المحافظات التالية: القاهرة، الاقصر ،

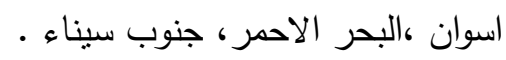

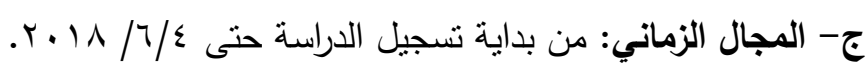

\section{السواسمة الميتانهي}

$$
\text { وصف فيلى اهم دلالات البيانات الاحصائية: }
$$

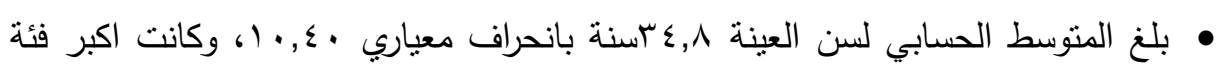

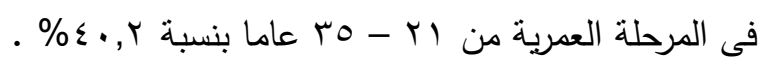

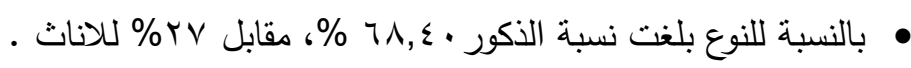

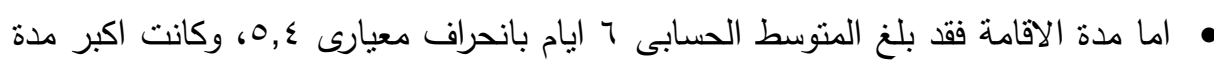

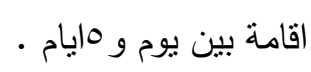

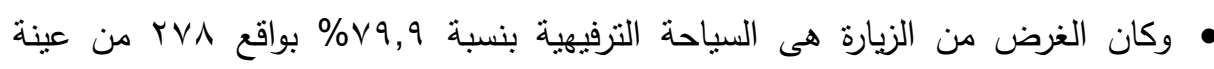
الدراسة . وان التعض 
• شملت الديانة كل من الديانة الاسلامية والمسيحية والهندوسية وكانت اعلى نسبة من عينة

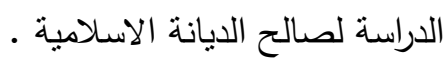

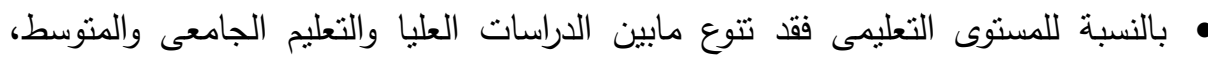

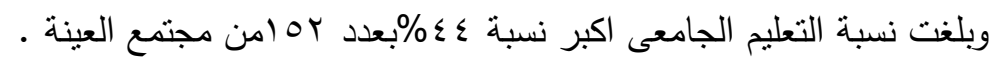

وكانت مصادر الحصول على المعلومات للسائحين مختلفة ومن اكثر من مصدر مثل )

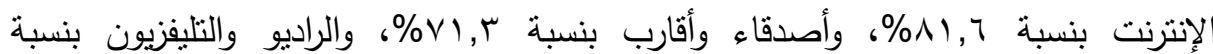

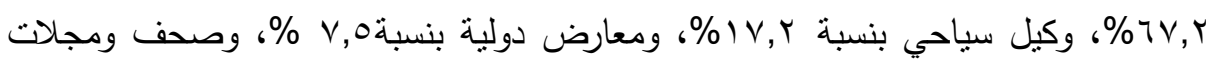

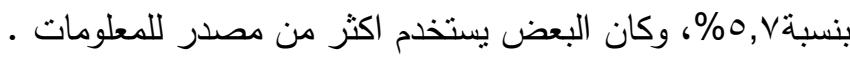

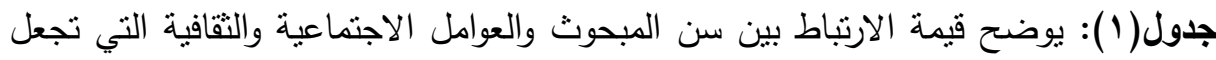

\begin{tabular}{|c|c|c|c|c|}
\hline 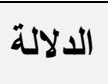 & الإزتباطة & 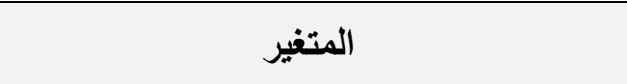 & & r \\
\hline$\cdot, Y 19$ & $\cdot, \cdot \vee \vee 9-$ & السمعة الإيجابية للمقصد السياحى & \multirow{7}{*}{$\begin{array}{l}3 \\
\overline{3} \\
\overline{3} \\
3 \\
3\end{array}$} & 1 \\
\hline$\cdot, 1 \mu$ & $\cdot, 1 \mu V-$ & الرغبة في التعرف على العادات والتقالبد للسكان & & $r$ \\
\hline$\cdot, \cdots$ & $\cdot, r \leqslant q-$ & التعرف على المعتقدات الدينية للسكان المحليين & & $r$ \\
\hline$\cdot, \cdot M$ & $\cdot, 1 \leq Y-$ & التعرف على الحضارة المصرية القديمة & & $\varepsilon$ \\
\hline$\cdot, \cdot 19$ & $\cdot, \mid \vee 1-$ & السياحة الثقافية والأثرية & & 0 \\
\hline$\cdot, \cdots$ & $\cdot, Y Y I-$ & السياحة الدينية & & 7 \\
\hline$\cdot, \cdots$ & • & الأنشطة الترفيهية والحياة الليلية & & $\mathrm{V}$ \\
\hline
\end{tabular}
المبحوثين يرغبون في زيارة مصر

العبارات المظلة دالة والعبارات الغير مظللة غير دالة

التحليل الاحصائى: يوضح جدول (1) قيمة الارتباط بين سن المبحوثين والعوامل الاجتماعية والثقافية التي تجعل المبحوثين يرغبون في زيارة مصر والذى تنين منه انه كلما قل سن المبحوثين كانوا اكثر اهتماما ورغبة فى التعرف المعتقدات الدينية للسكان المحليين والحضارة المصرية القديمة ،والسياحة الثقافية والأثرية، والسياحة الدينية، والأنشطة الترفيهية التئية والحياة الليلية، بينما باقى العوامل لم تكن الفروق ذات دالة احصائيا ـ ـ 
التحليل والتفسير: ينضح من الجدول انه كلما كان السن صغير كان السفر اسهل وهناك حرية فى الانتقالات ورغبة اكثر فى التعرف والتقارب والاطلاع على كل ماهو مجهول بالنسبة

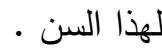
جدول(r): يوضح المقارنة بين الذكور والإناث من حيث العوامل الاجتماعية والثقافية التي تجعلهم يرغبون في زيارة مصر

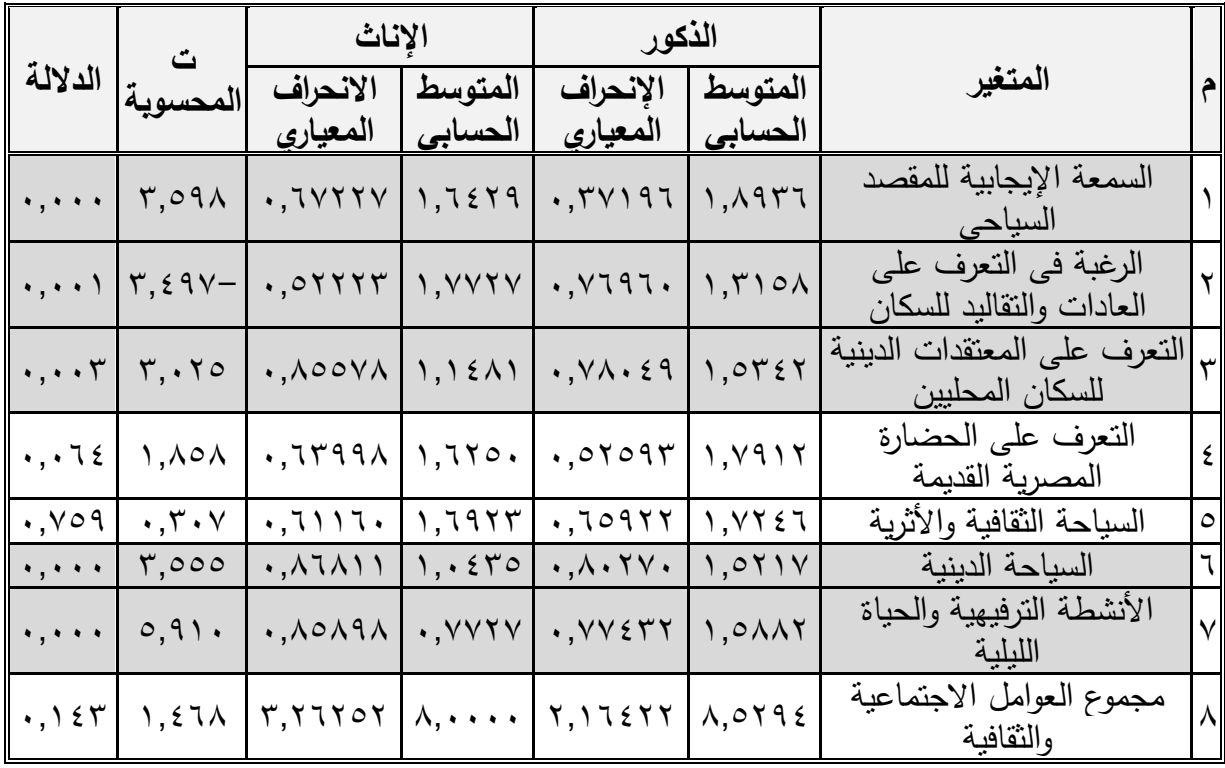

العبارات المظللة دالة وإلعبارات الغير مظلة غير دالة

التحليل الإحصائى: يوضح الجدول السابق بان المنوسطات الحسابية لكل من السمعة الإيجابية للمقصد السياحي، والتعرف على المعتقدات الدينية للسكان المحليين، السياحة الدينية، الأنشطة الترفيهية والحياة الليلية كانت مهمة بالنسبة للذكور اما بالنسبة للاناث فقد

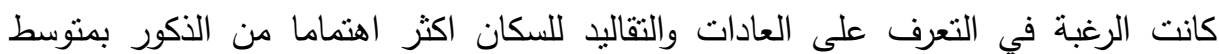

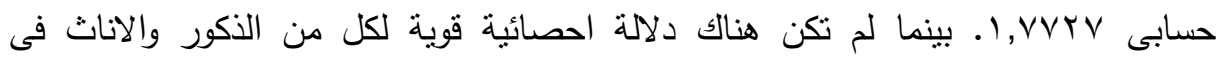

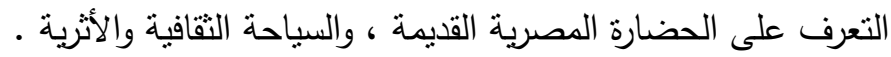
التحليل والتفسير: يتضح من الجدول ان الذكور لديهم الوقت واكثر ميلا من الاناث للمعرفة والقيام بالواجبات الدينية وايضا التمتع بالانثطة الترفهية ـ

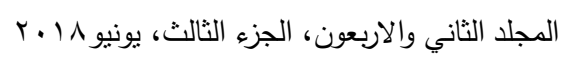


جدول(ץ): يوضح قيمة الارتباط بين مدة إقامة المبحوثين والعوامل الاجتماعية والثقافية التي تجعلهم يرغبون في زيارة مصر

\begin{tabular}{|c|c|c|c|c|}
\hline الالالة & قيمة الإرتباط & المتغير & & م \\
\hline$\cdot, 11 \% 9$ & $\cdot, .9 \mu-$ & السمعة الإيجابية للمقصد السياحى & \multirow{8}{*}{ 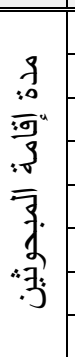 } & 1 \\
\hline$\cdot, \ldots 1$ & $\cdot, \Gamma q \wedge-$ & الرغبة في التعرف على العادات والتقاليد للسكان & & r \\
\hline$\cdot, \ldots 1$ & $\cdot, Y \circ \leqslant-$ & التعرف على المعتقدات الدينية للسكان المحليين & & $r$ \\
\hline$\cdot, \cdots$ & $\cdot$, Yrq- & التعرف على الحضارة المصرية القديمة & & $\varepsilon$ \\
\hline$\cdot, \ldots$ & $\cdot, \Gamma \cdot \varepsilon-$ & السياحة الثقافية والآثرية & & 0 \\
\hline$\cdot, .49$ & $\cdot, I M r-$ & السياحة الدينية & & 7 \\
\hline$\cdot, \cdot \Gamma$. & $\cdot, 177-$ & الأنشطة الترفيهية والحياة الليلية & & V \\
\hline$\cdot, Y \backslash \varepsilon$ & $\cdot, \cdot, 7 \Lambda-$ & مجموع العوامل الاجتماعية والثقافية & & $\Lambda$ \\
\hline
\end{tabular}

التحليل الاحصائى: يوضح جدول (r) قيمة الارتباط بين مدة إقامة المبحوثين والعوامل الاجتماعية والثقافية التي تجعلهم برغبون في زيارة مصر ، انه كلما قلت مدة الاقامة المبحوثين كان الاهتمام اكبر فى التعرف على العادات والتقاليد للسكان، والتعرف على المعتقدات الدينية للسكان المحليين، التعرف على الحضارة المصرية القديمة ،والسياحة الثقافية والأثرية، والسياحة الدينية، والأنشطة الترفيهية والحياة الليلية. بينما لا توجد دلالة احصائية قوية على قلة مدة اقامة المبحوثين وباقى العوامل الاجتماعية والثقافية التي تجعلهم يرغبون في زيارة مصر،

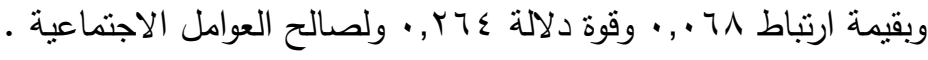
التحليل والتفسير: يوضح الجدول ان المدة الزمنية القصيرة للسائحين هى المدة الزمنية الاكثر شيوعا وتمكن السائحين من ممارسة هواياتهم، ولذا يمكن ان يتم زيادة هذه المدد مما

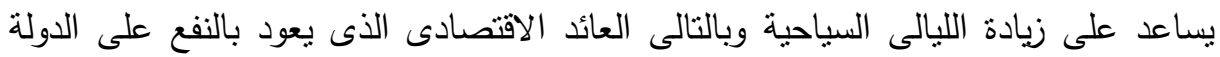
والمجتمع. 
جدول(؟): يوضح قيمة كاب بين الغرض من زيارة المبحوثين والعوامل الاجتماعية والثقافية

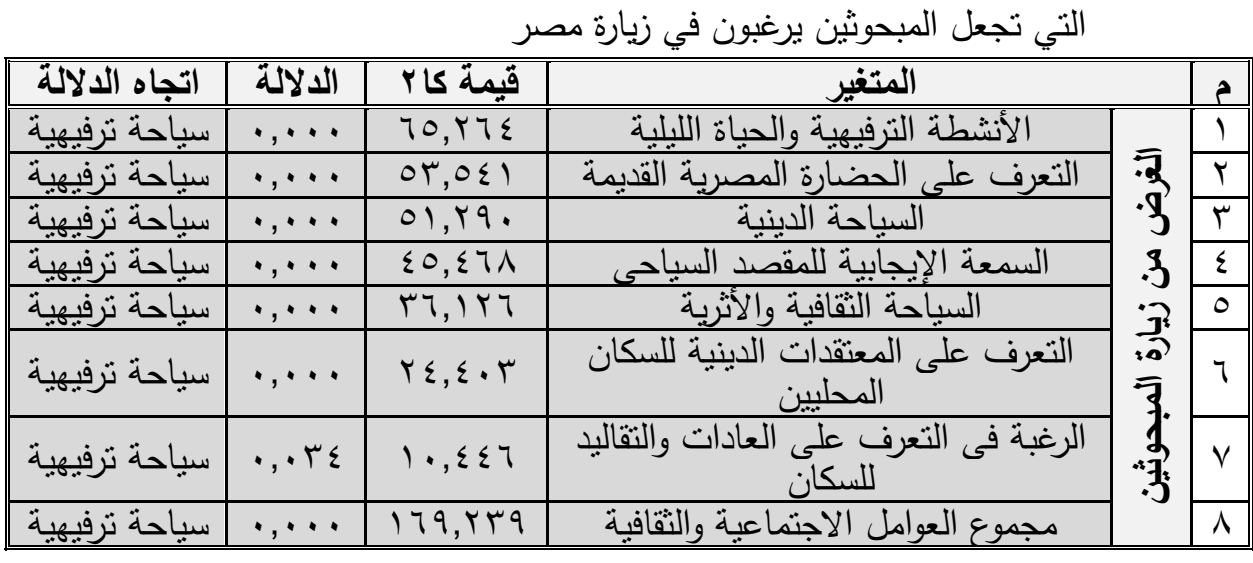

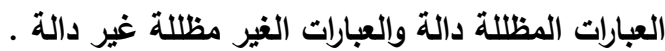

التحليل الاحصائى: يوضح جدول (ع) قيمة كاب بين الغرض من زيارة المبحوثين والعوامل الاجتماعية والثقافية التي تجعلهم يرغبون في زيارة مصر ، حيث نتير النتائج الى الايجابية

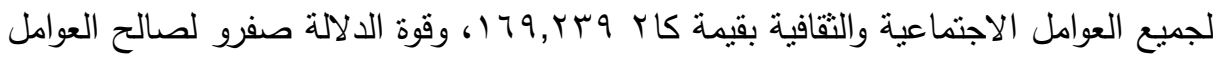

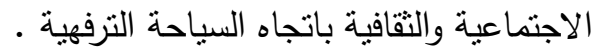
التحليل والتفسير: يفسر الجدول ان العوامل الاجتماعية من اسباب جذب السائحين ولا تعتبر عامل طرد. - مان جدول(0): يوضح قيمة كاب بين ديانة المبحوثين والعوامل الاجتماعية والثقافية التي تجعلهم يرغبون في زيارة مصر دين

\begin{tabular}{|c|c|c|c|c|c|}
\hline الاتلجةه & 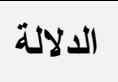 & قيمة كاب & المتغير & & م \\
\hline 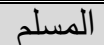 & $\cdot, \ldots$ & $r V, \Sigma)$. & السباحة الدينية . & \multirow{8}{*}{ 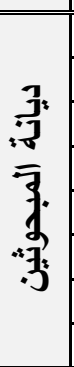 } & 1 \\
\hline المسلح & $\cdot, \ldots$ & $r \cdot, \Sigma q V$ & التعرف على الحضارة المصرية القديمة. & & T \\
\hline المسلح & $\cdot, \ldots$ & TY,0T. & الآنشطة الترفيهية والحياة الليلية. & & $r$ \\
\hline المسلم & $\cdot, \ldots$ & $r \cdot, 707$ & السمعة الإيجابية للمقصد السياحى. & & $\varepsilon$ \\
\hline 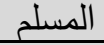 & $\cdot, \ldots 1$ & $11, \cdot \leq 0$ & السياحة الثقافية والأثرية. & & 0 \\
\hline 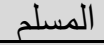 & $\cdot, \ldots r$ & $17, .0 Y$ & التعرف على المعتقدات الدينية للسكان المحليين. & & 7 \\
\hline 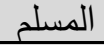 & $\cdot, \cdot, Y Y$ & $11, \varepsilon \vee \varepsilon$ & الرغبة في التعرف على العادات والنقاليد للسكان. & & $\mathrm{V}$ \\
\hline المسلم & $\cdot, \ldots$ & 01,170 & مجموع العوامل الاجتماعية والنقافية & & $\Lambda$ \\
\hline
\end{tabular}

العبارات المظللة دالة والعبارات الغير مظللة غير دالة الئة

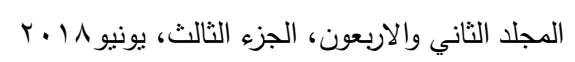


التحليل الاحصائى: بالنظر الى جدول رقم (0) الذى يوضح العلاقة بين ديانة المبحوث وتاثثرها على العوامل الاجتماعية والثقافية المؤثرة في زيارتهم لمصر، نتشير النتائج بتاثير الديانة على العوامل الاجتماعية والثقافية لصالح الديانة الاسلامية، وبمجموع العوامل

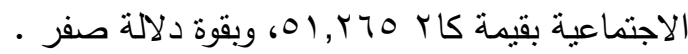
التحليل والتفسير: بالنظر الى الجدول يلاحظ ان ديانة السائحين تاثرت بالعوامل الاجتماعية والثقافية باختيارهم للسياحة الدينية حيث تعتبر مصر ارض الحضارات ومهد

جلول(ا): يوضح قيمة كاب بين مستوى تعليم المبحوثين والعوامل الاجتماعية والثقافية التي تجعهم يرغبون في زيارة مصر

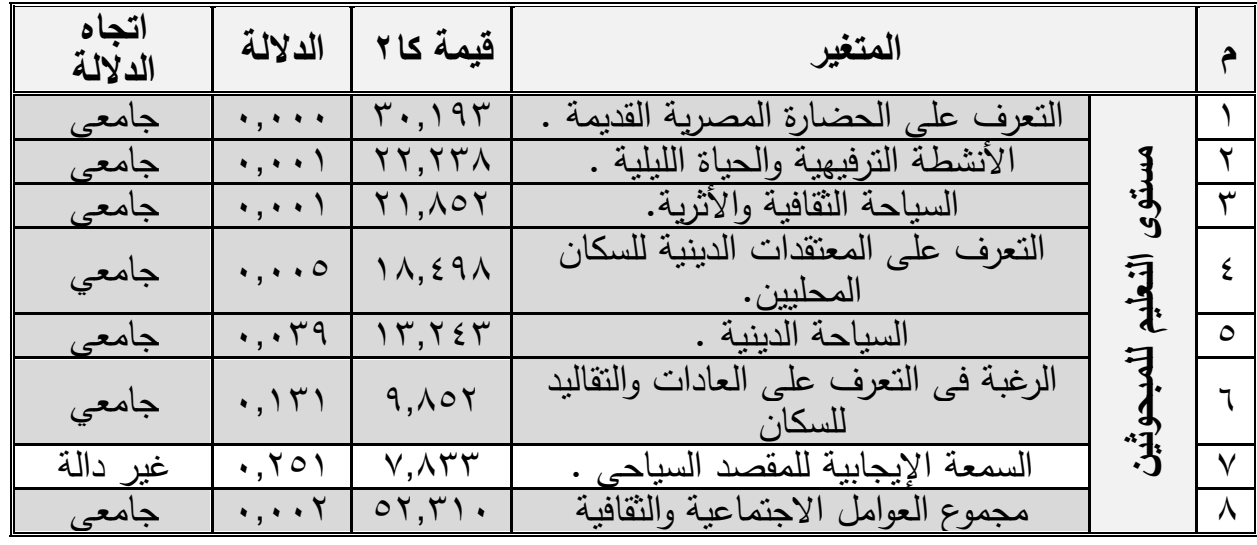

العبارات المظللة دالة والعبارات الغير مظللة غير دالة .

التحليل الاحصائى: جدول (T) يوضح قيمة كاب بين مستوى التعليم للمبحوثين والعوامل الاجتماعية والثقافية التي تجعلهم يرغبون في زيارة مصر فقد انشار التحليل الى انه كلما ارتفع مستوى التعليم كان الاهنمام اكثر فى التعرف على الحضارة المصرية القديمة، والأنشطة الترفيهية والحياة الليلية والسياحة الثقافية والأثرية، والتعرف على المعتقدات الدينية للسكان المحليين، والسياحة الدينية، والرغبة في التعرف على العادات والتقاليد للسكان. بقيمة كاب البه

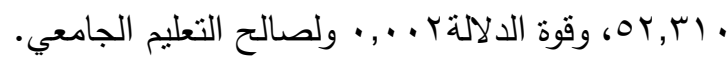


التحليل والتفسير: ان مستوى التعليم يتيح للتنعلم ان يعرف ويقرا ويفهم وييحث عن المقاصد السياحية المتاحة امامه والمفاضلة بينهم، ولكن هناك فئة لا يجب اغفالها والتوجيه نحو التعامل معهم بما يناسبهم فى اختبارتهم وتوعيتهم باهمية السياحة وتاثيرها الفرد من وجود ولهن نشاط جديد يعمل على اسعاده . جدول(V): إنوضح جنسية المبحوثين

\begin{tabular}{|c|c|c|c|}
\hline النسبة \% & العدد & الجنسية & P \\
\hline$\% \circ 9, \wedge$ & $r \cdot \Lambda$ & إندونيسيا & 1 \\
\hline$\%\{, 7$ & 17 & السعودية & T \\
\hline$\% \varepsilon,$. & $1 \varepsilon$ & أمربكا & $r$ \\
\hline$\%$ \%, ६ & IT & الهند & $\varepsilon$ \\
\hline$\% \curlyvee, q$ & 1. & آلمانيا & 0 \\
\hline$\% \curlyvee, r$ & $\Lambda$ & الكويت & 7 \\
\hline$\% Y, r$ & $\Lambda$ & الإمارات & $\mathrm{V}$ \\
\hline$\% 1, \vee$ & 7 & قطر & $\Lambda$ \\
\hline$\% ।, \vee$ & 7 & البحرين & 9 \\
\hline$\% ।, \vee$ & 7 & الجزائر & 1. \\
\hline$\% ।, \vee$ & 7 & إسبانيا & 11 \\
\hline$\% ।, \vee$ & 7 & فرنسا & IT \\
\hline$\% 1,1$ & $\varepsilon$ & إيطاليا & $1 \pi$ \\
\hline$\% 1,1$ & $\varepsilon$ & إيرلندا & $1 \varepsilon$ \\
\hline$\% \cdot, 7$ & T & الإرجنتين & 10 \\
\hline$\%,, 7$ & $\bar{r}$ & كوريا & 17 \\
\hline$\% \cdot, 7$ & $\bar{r}$ & آيسلاند & IV \\
\hline$\% \cdot, 7$ & T & تركيا & 11 \\
\hline$\% \cdot, 7$ & $Y$ & المكسيك & 19 \\
\hline$\% \cdot, 7$ & r & تونس & $r$. \\
\hline$\% \cdot, 7$ & Y & بريطانيا & YI \\
\hline$\% \cdot, 7$ & r & لبنان & $\overline{Y Y}$ \\
\hline$\% \cdot, 7$ & $r$ & السودان & $\overline{r T}$ \\
\hline$\%\{, 7$ & 17 & غير مبين & $\overline{r \varepsilon}$ \\
\hline$\%, \ldots$ & $r \leqslant \Lambda$ & يموع & \\
\hline
\end{tabular}

التحليل الاحصائى: يوضح الجدول الجنسيات المختلفة لعينة المبحوثين ومنه تنين التتوع الكبير فى جنسيات السائحين الوافدين الى مصر يصل الى بr جنسية مابين العربية،

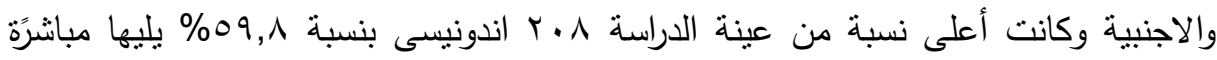

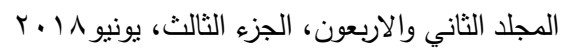


الجنسية السعودية حيث وصلت النسبة 7,ء٪، يلي ذلك الجنية الامريكية حيث وصلت

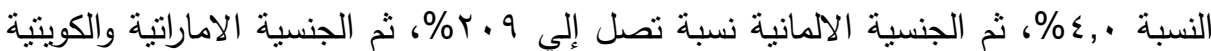
بنسبة r,r \% لكل منهم، ثم الجنسية البحرانية والقطرية والجزائرية والاسبانية والفرنسية بنسبة

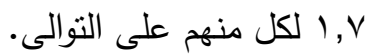

التحليل والتفسير: نتير نتائج جدول V) الى تتوع الجنسيات الوافدة الى مصر وان اختلفت الاعداد مما يتطلب الاهتمام بالجنسيات الحالية والتوجه الى جنسيات اخرى اقل عددا

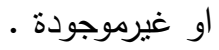

جلول(^): يوضح قيمة كاب بين جنسية المبحوثين والعوامل الاجتماعية والثقافية التي تجعلهم

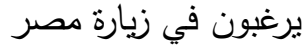

\begin{tabular}{|c|c|c|c|c|c|}
\hline الدالنة & الدلالة & قيمة كا؟ & المتغير & & b \\
\hline إندونبسيا & $\cdot, \ldots$ & rol, rvq & السياحة الدينية & \multirow{8}{*}{$\frac{\sqrt{3}}{\frac{3}{3}}$} & 1 \\
\hline إندونيسيا & $\cdot, \ldots$ & $\mu \cdot, \Sigma \wedge \wedge$ & السمعة الإيجابية للمقصد السياحى & & $r$ \\
\hline إندونيسيا & $\cdot, \cdots$ & $r \wedge 1, r \leq 7$ & التعرف على الحضارة المصرية القديمة & & $\mu$ \\
\hline إندونيسيا & $\cdot, \cdots$ & $r \leq 1,97 r$ & الأنشطة الترفيهية والحياة الليلية & & $\varepsilon$ \\
\hline إندونيسيا & $\cdot, \cdots$ & $r+q, r ו 1$ & السياحة الثقافية والآثرية & & 0 \\
\hline إندونيسيا & & $1 \wedge 7, Y \leqslant 0$ & المحليين على المعتقدات الدينية للسكان & & 7 \\
\hline إندونيسيا & $\cdot, \cdots$ & $1 \cdot r, \cdot \leqslant q$ & للسكانة فى التعرف على العادات والتقاليد & & v \\
\hline إندونيسيا & $\cdot, \ldots$ & Iror,YVT & مجموع العوامل الاجتماعية والثقافية & & $\Lambda$ \\
\hline
\end{tabular}

التحليل الاحصائى: بالنظر الى جدول رقم (^) الذى يوضح العلاقة بين جنسية المبحوثين والعوامل الاجتماعية والثقافية التي تجعلهم يرغبون في زيارة مصر، تشير النتائج الى ان الجنسية توافقت مع العوامل الاجتماعية والثقافية بالترتيب كالاتى : السياحة الدينية، والسمعة الإيجابية للمقصد السياحي، والتعرف على الحضارة المصرية القديمة، والأنشطة الترفيهية والحياة الليلية والسياحة التقافية والأثرية، اما بالنسبة لكل من التعرف على المعتقدات الدينية 
للسكان المحليين لم يتوافقوا عليها، وكذلك الرغبة في التعرف على العادات والتقاليد للسكان

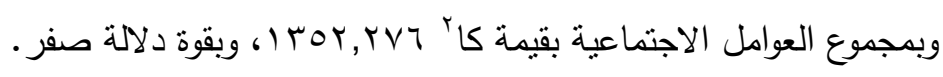

التحليل والتفسير: بالنظر الى الجدول بلاحظ عدم وجود فروق معنوية بين افراد عينة الدراسة حول تاثر جنسية السائحين بالعوامل الاجتماعية والتقافية.

\section{stl}

ابراهيم مصطفى، وأحمد الزيات، وحامد عبدالقادر، ومحمد النجار، المعجم الوسيط،

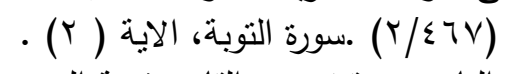

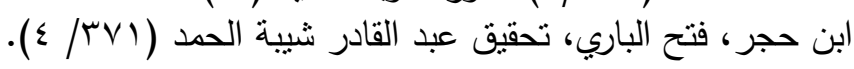

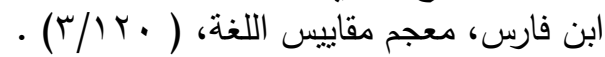

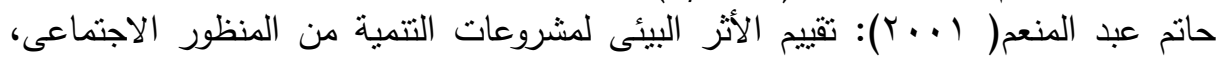

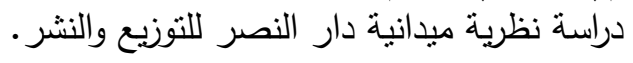

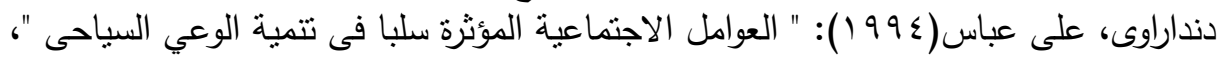

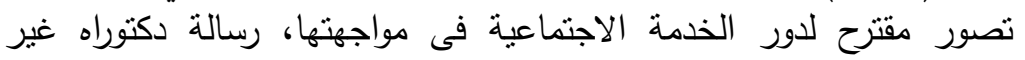

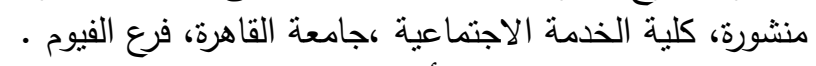

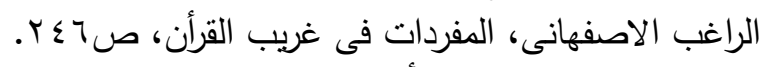

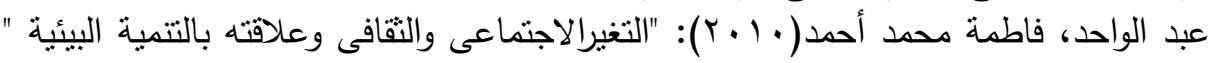

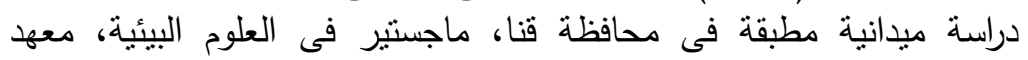

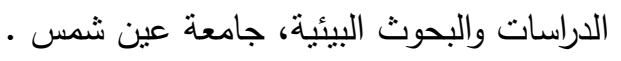

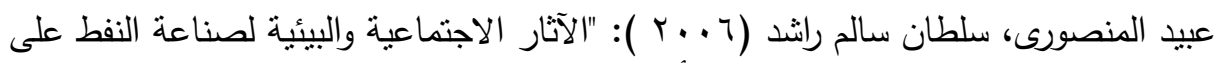

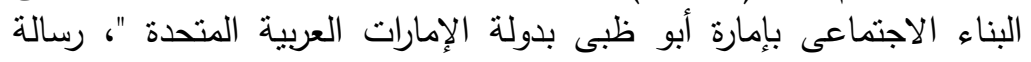

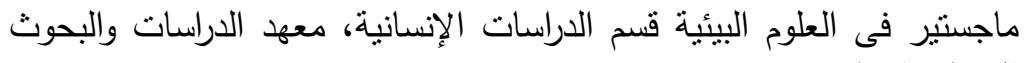

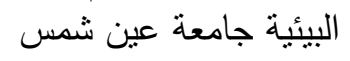

عزيز حنا داوود وآخرون(199 (1)): مناهج البحث في العلوم السلوكية، القاهرة، مكتبة الأنجلو

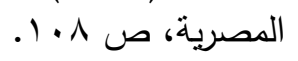

منظمة السياحة العالمية .

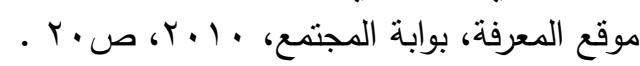

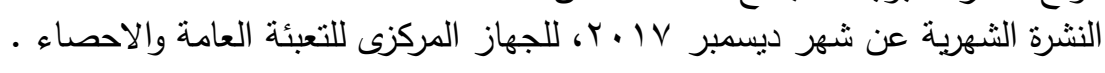


Bikmaniene , R. (2004): “Effects of social tourism on society ", Public Healthcare .

Davidson , R ( 1993 ): “ Tourism “, Pitman , London

\title{
STUDY OF SOME SOCIAL AND PHYSICAL VARIABLES AFFECTING THE INCOMING TOURISTS - A COMPARATIVE STUDY AMONG DIFFERENT SEGMENTS OF THE EGYPTIANS AND THE TOURISTS
}

\begin{abstract}
Abdel Menem, H. $^{(1)}$; Samy, H. $^{(2)}$ and El-Helew, Nadia, A. S. ${ }^{(3)}$ 1) Institute of Environmental Studies \& Research- Ain Shams University 2) The Higher Institute for Tourism \& Hotels 3) Ministry of Tourism
\end{abstract}

\begin{abstract}
Egypt considers one of the tourist states on which the tourist activity is considered one of the solutions for increasing national income and restricting the unemployment. Despite the great significance and multiple benefits of the tourist activity and its active role in total development, it is unstable and quick-affected by the surrounding circumstances of the hosting countries for tourists. It is also influenced by some other internal and external factors. For instance, Egyptian tourism is currently suffering from political security instability in addition to some negative security, behavioral, and social factors.
\end{abstract}

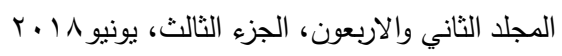


This present study drives at identifying or reaching some social variables that affect the imported tourism for the purpose of reaching possible solutions for problems encounter this imported tourism. The study uses the scientific method using the social survey and being applied on a random sample of (348) tourists from different nationalities, using a questionnaire form to be administered on four governorates (Luxor - Aswan - The Red Sea - Sharm El-Sheikh), in addition to hotels' guests in some hotels and visitors of the Egyptian Museum. The researcher uses other tools including a questionnaire Form, case study, and review of literatures. The ecological system theory has been the intellectual orientation for the researcher as it collects between System theory and the Human Ecology, meaning the exchanged interactions between physical factors and living creatures.

\section{The study comes to several important results including:}

- Tourists in the age stage (21-35 yrs.) represent 68\% of the total sample and they are interested in identifying the religious beliefs, ancient Egyptian civilization, monumental tourism, and religious tourism.

- Males are the most important category in tourism as they represent $68 \%$ of the sample and they care about the positive reputation of the tourist areas and identifying the habits, traditions, and religious beliefs of the original local inhabitants besides the recreational activities.

- The stay period has differed for tourists with least period (5 days), as they care about identifying habits, traditions, and religious beliefs of the original local inhabitants, in addition to the recreational activities, night life, and religious visits.

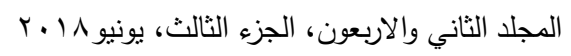

